УДК 005.8:005.41

\author{
О. В. Сгорченков ${ }^{1}$, к.т.н., доцент, \\ e-mail: alexee@ukr.net \\ Є. Ю. Катаєва ${ }^{2}$, к.т.н., доиент, \\ e-mail: kataevae@ukr.net \\ Ю. Л. Хлевна ${ }^{1}$, к.т.н. \\ e-mail: yuliya.khlevna@gmail.com \\ ${ }^{1}$ Київський національний університет імені Тараса Шевченка \\ вул. Володимирська, 60/13, м. Київ, 01601, Україна \\ ${ }^{2}$ Черкаський державний технологічний університет \\ б-р Шевченка, 460, м. Черкаси, 18000, Україна
}

\title{
ПОНЯТІЙНИЙ АПАРАТ УПРАВЛІННЯ ПОРТФЕЛЯМИ ПРОЕКТІВ І ПРОГРАМ В 4П-СЕРЕДОВИЩІ
}

Одна з проблем сучасного проектного менеджменту полягає в тому, що зазвичай на підприємствах для управління проектами використовуються різні інструментальні програмні засоби, які вирішують різні функиіональні задачі: планування, контролю, економічної та фiнансової оцінки та ін. Традиційно задачі інтеграції інформації в таких системах розглядаються в рамках способів управління інформаиійним зв'язком у проектах. Однак з підвищенням рівня інформатизачії проектно-орієнтованих підприємств використання різноманітних інформачійних систем для вирішення функиіональних задач виявляється недостатньо. Тому в статті пропонуеться створити концепцію управління портфелями проектів і програм проектно-орієнтованих підприємств, яка об'єднує сфери управління проектами $і$ організачіями в єдине функиіональне середовище - 4П-середовище. Науково-методологічний базис побудови 4П-середовища необхідний для того, щоб на основі розроблених моделей і методів створювати структури, алгоритми, засоби та прочеси функиіональних надбудов над інструментальними засобами управління проектами на проектно-орієнтованих підприємствах. По суті, такий базис дасть можливість створити множину функиіональних операторів, які задовольнять потребу проектного менеджменту в сучасній інформаційній технологї управління.

Ключові слова: 4П-середовище, портфель проектів і програм, проектний менеджмент, інформаційні технології.

Вступ. Діяльність проектноорієнтованих підприємств у нашій країні і за кордоном характеризується складністю і невизначеністю, значною залежністю від динамічного оточення, що включає соціальноекономічні, політичні, фінансово-економічні, законодавчі впливи як держави, так і конкуруючих підприємств, а також партнерів по бізнесу. Тому відсутність систем, що забезпечують ефективне управління підприємствами, проектами, програмами і портфелями проектів, призводить до неефективності управлінських рішень, виконання непотрібних робіт або нескоординованої їх реалізації, збитків, авралів, зривів робіт за найважливішими контрактами, численних проблем. Веління часу - змінити такий стан справ, знайти наукові методи створення систем управління всіма видами діяльності проектно-орієнтованих підприємств.

Одна 3 проблем сучасного проектного менеджменту полягає в тому, що зазвичай на підприємствах для управління проектами використовуються різні інструментальні програ- мні засоби (MS Project, Oracle Primavera P6, Clarizen, Project Expert та ін.), які вирішують різні функціональні задачі: планування, контролю, економічної та фінансової оцінки та ін. Традиційно задачі інтеграції інформації в таких системах розглядаються в рамках способів управління інформаційним зв'язком у проектах. Однак з підвищенням рівня інформатизації проектно-орієнтованих підприємств, використанням для вирішення функціональних задач різноманітних інформаційних систем (далі - IC) цього виявляється недостатньо. Ще більше ускладняється ця задача, коли вимагається управляти масштабними програмами чи портфелями проектів і програм. Виникають нові проблеми - координації діяльності, розподілу ресурсів, пріоритезації проектів і програм, формування команд, виконання виробничих чи управлінських функцій підприємства не в розрізі окремих проектів, а по портфелю в цілому. I тут виникає ще один рівень складності. Задачі управління портфелями проектів $\mathrm{i}$ програм перетинаються 3 функціональними 
задачами управління самим підприємством. Виходячи 3 цього, на перший план виступає задача створення єдиного функціонального середовища управління проектами, програмами, портфелями проектів та програм і проектно-орієнтованим підприємством (4Псередовища), яке б включало інструменти, задіяні як у проектній, так і в операційній діяльності підприємства і забезпечувало б системний (синергетичний) ефект від вирішення комплексу задач управління портфелями проектів і програм як єдиної системи функцій.

Необхідно закласти концептуальний фундамент науково-методологічного базису функціонального 4П-середовища проектноорієнтованих підприємств, в яке будуть інтегровані управлінські процеси різноманітних інструментальних систем управління проектами, програмами, портфелями і операційною діяльністю.

На відміну від ERP систем, де функції управління ресурсами підприємств доповнюються модулями управління проектами, створення функціонального 4П-середовища полягає в доповненні інструментальних програмних засобів управління проектами функціями, які дають змогу інтегрувати їх як 3 процесами управління портфелями проектів і програм, так i 3 процесами управління самим проектноорієнтованим підприємством. Це, 3 одного боку, знизить вартість засобів управління проектами, а з другого, підніме їх функціональну повноту. На сьогодні найбільш повною в функціональному розумінні відповідно до поставленої задачі $є$ Oracle Primavera. Але навіть у цьому засобі немає багатьох функцій, які б дозволяли ефективно інтегрувати його в функціональне середовище управління підприємством. Тому $є$ необхідність у створенні такого функціонального середовища, яке було б повним відносно процесів управління проектами/програмами/портфелями і проектною діяльністю проектно-орієнтованого підприємства.

Аналіз основних досліджень і публікацій. У процесі розширення і розвитку підприємства, збільшуючи кількість проектів, формують портфелі проектів і програм, спрямовані на впровадження інноваційних технологій, випуск нових продуктів і т. д. В основному підприємствам 3 відсутністю формалізованого управління портфелями проектів не вдається досягти повернення вкладених інвестицій [1].

Управління портфелем дозволяє визначити найбільш вигідні для підприємства шляхи розвитку, з огляду на фінансові та ресурсні обмеження, ризики, прийняті політики і правила, i тому $є$ природним розвитком проектного менеджменту на підприємстві [2]. Управління портфелями проектів та програм відрізняється від управління проектом тим, що основним завданням проектного управління $€$ «робити роботу правильно», а управління програмою і портфелем - «робити правильні роботи», що істотно розширює коло проблем [3].

Основні проблеми, що виникають у процесі управління портфелями проектів більшості проектно-орієнтованих підприємств [4]:

1. Реалізація одночасно великої кількості проектів у портфелі, цілі яких дублюються.

2. Неправильний вибір проектів, реалізація проектів, які не становлять цінності для підприємства.

3. Відсутність орієнтації на досягнення стратегічних цілей підприємства

4. Незбалансованість портфеля проектів (недооблік основних можливостей для отримання прибутку; недооблік основних ризиків; зайва кількість проектів, спрямованих на виробничі аспекти, при нестачі проектів, що стосуються ринкових аспектів діяльності підприємства).

5. Відсутність методологій управління портфелями проектів, які можуть налаштовуватись на специфіку конкретного підприємства [5].

Професорами маркетингу канадського університету McMasterUniversity Р. Купером, С. Еджетом, Е. Кляйншмідт у 2000 р. були проведені наукові дослідження в галузі управління портфелем проектів [6]. В результаті цих досліджень виявлено наступні основні проблеми, 3 якими стикалися підприємства під час керування портфелями проектів та програм:

1. Велика кількість проектів, які долають бар'єр на включення в список виконуваних проектів, тому що на ранній стадії важко оцінити, який проект кращий, а який гірший.

2. Вимоги ресурсів для потреб проектів, які значно перевищують їх наявність.

3. Недостатність інформації при прийнятті рішення про долю проектів.

4. Занадто велика кількість маленьких проектів у портфелі.

На думку вищезазначених учених, ці проблеми викликані:

- недостатністю інформації для прийняття рішень;

- розбалансованістю стратегічних і тактичних проектів; 
• недосконалістю методів і моделей управління портфелем проектів.

На шляху забезпечення якості управління портфелями проектів в проектноорієнтованих підприємствах трапляються проблеми, пов'язані з відсутністю орієнтованих на підприємство методологій, які могли б забезпечити можливість визначення:

- раціонального переліку робіт, необхідного для управління портфелем проектів;

- переліку робіт з управління проектами за умов обмеженості фінансових ресурсів;

- необхідного методу, який би забезпечив ефективне управління змінами в переліку робіт $з$ управління портфелем проектів на базі аналізу пріоритетних критеріїв реалізації портфеля.

У зв'язку з зазначеним вище зауважимо, що велика кількість досліджень [7-17] присвячена створенню інформаційних систем для управління портфелями проектів та програм. Це пов'язано $з$ тим, що в процесі УППП керівнику необхідно оперувати великою кількістю мінливих даних (терміни, витрати, ресурси тощо), які супроводжують кожний проект портфелю і управляти якими можна тільки за допомогою спеціального програмного забезпечення

На сьогоднішній день у наукових та практичних дослідженнях пропонується для управління ППП застосування таких інформаційних систем, як Oracle Primavera [18], MS Project [19], ERP систем [20]. Застосування цих та інших програмних продуктів має ряд переваг, таких як можливість планувати та контролювати ресурси підприємства, які задіяні як у проектній, так і в операційній діяльності підприємства. Однак, разом 3 тим, існують і недоліки, зокрема відсутність можливості застосувати процеси, які не включені до функціоналу програмного засобу, але які $\epsilon$ необхідними для управління портфелем проектів (документообіг, виробництво матеріально-технічних ресурсів та ін.).

Отже, в результаті аналізу було визначено, що функціонал сучасних інформаційних технологій управління проектами не охоплює усі функції, які реалізуються в процесі управління проектами, портфелями проектів та програмами проектно-орієнтованого підприємства. Таким чином, необхідно створити деяку технологію управління портфелями, програмами, проектами і підприємствами, яка буде включати неохоплені функції управління. Для реалізації такої технології, перш за все, необхідно сформувати концептуальні засади, основою яких є понятійний апарат управління портфелями проектів і програм у 4П-середовищі.

Формулювання цілей статті. Метою статті $\epsilon$ визначення понятійного апарату управління портфелями проектів і програм в 4П-середовищі.

Основний матеріал досліджень

Визначення 1. Функціональне 4Псередовище (або просто 4П-середовище) систематизована сукупність функцій управління проектами, програмами, портфелями проектів і програм та проектно-орієнтованим підприємством (в частині управління проектами, програмами і портфелями), які використовують єдиний інформаційний ресурс і забезпечують системний (синергетичний) ефект від вирішення комплексу задач управління проектно-орієнтованими бізнесами підприємств і організацій.

Визначення 2. 4П-управління - управління проектами, програмами, портфелями проектів і програм i проектно-орієнтованим підприємством (в частині управління проектами, програмами і портфелями), яке здійснюється з використанням функцій 4П-середовища.

Конкретизована умовами проектноорієнтованого підприємства методологія управління портфелями проектів і програм повинна об'єднувати сфери управління проектами і організаціями в єдине функціональне середовище, в яке інтегруються окремі моделі, методи i засоби управління проектами, програмами, портфелями проектів і програм та операційною діяльністю підприємства. На сьогодні існує безліч засобів управління проектами, які не охоплюють усі задачі, 3 якими стикаються керівник і команда проекту в процесі роботи над проектом, які не дозволяють ефективно управляти масштабними програмами і портфелями проектів та програм і які не інтегруються 3 забезпечувальними функціями управління підприємством стосовно проектів/програм/портфелів (рис. 1).

У цьому випадку значна кількість функцій реалізується працівниками підприємства без використання спеціальних програмних засобів, що значно знижує рівень ефективності управління на цьому підприємстві.

Щоб усунути цей недолік, пропонується в рамках конкретизованої методології управління проектами створити таке функціональне середовище 4П-управління, яке було б максимально повним відносно тих функцій, з якими стикається менеджмент проектів i підприємств при організації управління чи управлін- 
ні проектами/програмами/портфелями цього підприємства. Таке середовище отримало назву функціонального 4П-середовища (див. визначення 1). Функціональне 4П-середовище містить дві складові: процедурну (реалізацію самих функцій) та інформаційну (інформаційний ресурс для реалізації цих функцій) Дамо визначення цим складовим 4П-середовища.

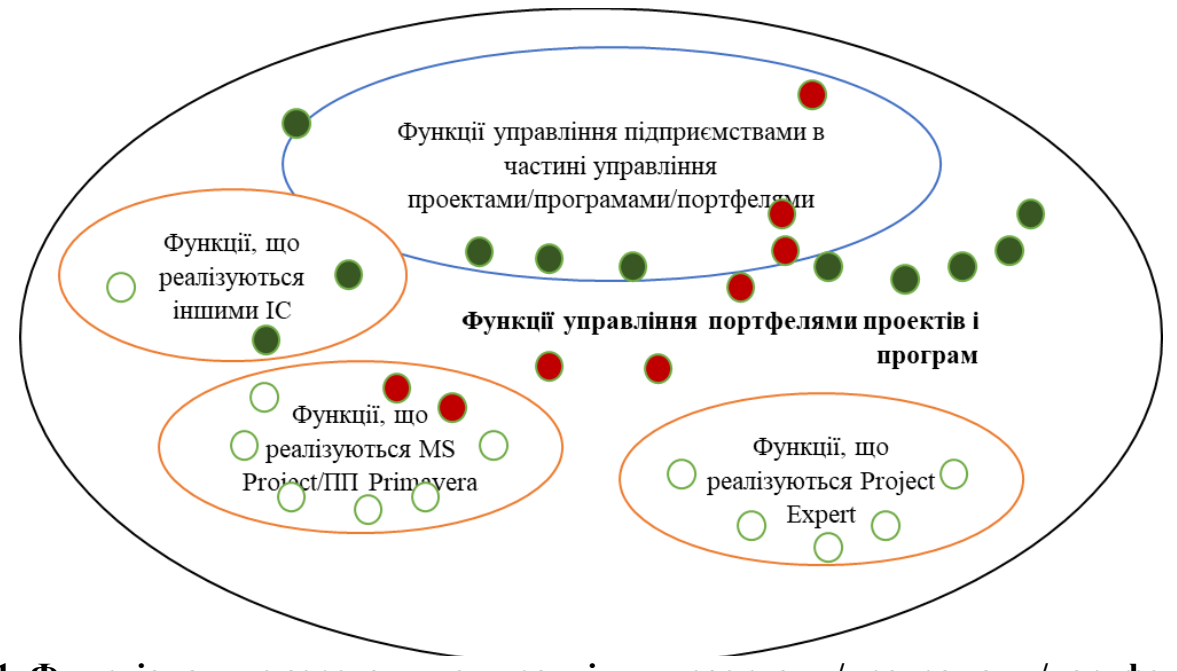

Рис. 1. Функціональне середовище управління проектами/програмами/портфелями на проектно-оріснтованому підприсмстві

Визначення 3. Інформаційна складова функціонального середовища управління проектами/програмами/портфелями і проектно-оріснтованим підприсмством (в частині управління проектами/програмами/портфелями) (4ПІ-середовище) - множина інформаційних ресурсів, які використовуються інструментальними засобами та засобами, якими доповнюються ці інструментальні засоби з метою максимально повної автоматизації процесів управління проектами/програмами/портфелями.

Визначення 4. Процедурна складова функціонального середовища управління проектами/програмами/портфелями та проектно-оріснтованим підприсмством (в частині управління проектами/програмами/портфелями) (4ППсередовище) - програмно-інформаційна система чи іï модуль, який реалізує функції управління проектами/програмами/портфелями чи управління підприємством (в частині управління проектами/програмами/портфелями), яку необхідно реалізувати або в рамках управління проектами/програмами/портфелями, або для забезпечення процесів управління проектами/програмами/портфелями.

4ПП-середовище наповнюється функціональними операторами.

Визначення 5. Функціональний оператор 4ПП-середовища - програмний засіб, який реалізує окрему процедуру управління проектами/програмами/портфелями чи управ- ління підприємством (в частині управління проектами/програмами/портфелями).

Кожний функціональний оператор реалізується або в рамках управління проектами/програмами/портфелями, або для забезпечення процесів управління проектами/програмами/портфелями. I кожний функціональний оператор реалізує деяку функцію управління, наприклад: збір інформації про необхідні ресурси, планування періоду, організація засідання тендерного комітету та ін.

$$
\text { Структурним елементом 4ПІ- }
$$
середовища $є$ інформаційний ресурс.

Визначення 6. Інформаційний ресурс 4ПІ-середовища - набір даних чи знань, готовий до використання функціональними операторами 4П-середовища.

Як видно 3 рис. 1, частина функцій управління проектами/програмами/портфелями реалізується сучасними інструментальними програмними засобами управління проектами, частина - різноманітними IC, а частина - виконується працівниками підприємства без використання спеціалізованих програм. Наприклад, при формуванні бюджету підприємства ведеться збір інформації як з проектів, так і 3 підрозділів, які проводять операційну діяльність. Сучасні інструментальні програмні засоби управління проектами не дозволяють сформувати бюджет підприємства (в частині реалізації проектів) за стандартами, прийнятими на підприємствах. От і доводиться працівникам більшості підприємств зводити всю інфо- 
рмацію по окремих проектах і операційній діяльності в єдину таблицю, використовуючи при цьому всім відомий офісний продукт MS Excel.

Щоб вирішити цю проблему, необхідно перенести частину функцій, які не реалізуються інструментальними програмними засобами, в деяку функціональну надбудову над цими засобами $\mathrm{i}$ розробити програмно- інформаційну систему, яка буде реалізовувати функціональні оператори по функціях, що не знайшли свого відображення в інструментальних програмних засобах (рис. 2). Така програмно-інформаційна система може створюватись як засобами самих інструментальних програмних систем, так і звичайними засобами програмування.

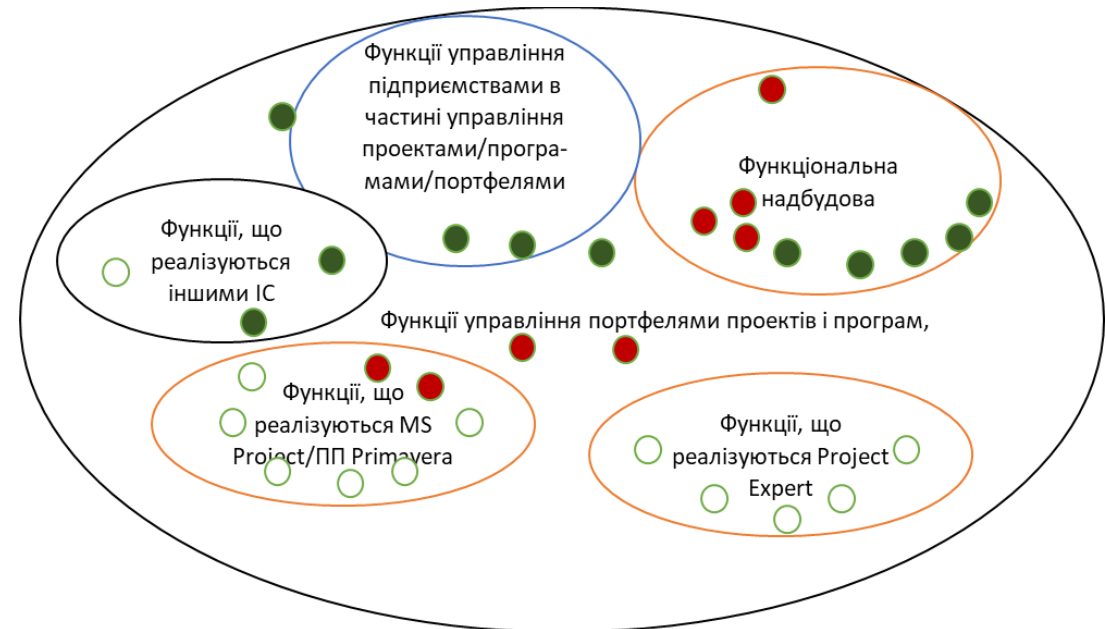

Рис. 2. Функціональне 4П-середовище управління проектами/програмами/портфелями на проектно-орієнтованому підприємстві

Висновки і перспективи подальших досліджень. Науково-методологічний базис побудови 4П-середовища необхідний для того, щоб на основі розроблених моделей і методів створювати структури, алгоритми, засоби та процеси функціональних надбудов над інструментальними засобами управління проектами на проектно-орієнтованих підприємствах. По суті, такий базис дасть можливість створити множину функціональних операторів, які задовольнять потребу проектного менеджменту в сучасній інформаційній технології управління.

Для вирішення цієї задачі необхідно визначити ті функції управління, які будуть відображені в функціональній надбудові і утворять 4П-середовище, що є темою для подальших досліджень.

\section{Список літератури}

1. Тернер Дж. Родни. Руководство по проектно-ориентированному управлению / пер. с англ. под. общ. ред. Воропаева В. И. Москва: ИД Гребенщикова, 2007. 522 с.

2. Матвеев А. А., Новиков Д. А., Цветков А. В. Модели и методы управления портфелями проектов. Москва: ПМСОФТ, 2005. 206 c.
3. Linenberg Y, Stadlker Z, Arbuthnot S. Optimizing organizational performance by managing project benefits. PMI Global Congress. 2003.

4. Кендалл Д. И., Роллинз С. К. Современные методы: управление портфелями проектов и офис управления проектами. СанктПетербург: Питер, 2004.

5. Teslia I., Yehorchenkov O., Khlevna I., Khlevnyi A. Development concept and method of formation of specific project management methodologies. Eastern-European Journal of Enterprise Technologies. 2018. № 5/3 (95). C. 616. DOI: https://doi.org/10.15587/17294061.2018.142707

6. Cooper Robert G., Edgett Scott J., Kleinschmidt Elko J. New problems, new solutions: making portfolio management more effective. Research. Technology Management. № 2. 43 p.

7. Єгорченкова Н. Ю. Інтеграція матричних технологій і методу критичних ланцюгів в управлінні ресурсами портфелів проектів і програм. Управління розвитком складних систем: зб. наук. праць. Київ, 2012. № 7. C. 30-35.

8. Тесля Н. Ю. Створення системи портфельного управління ресурсами компанії в проектах. Управління розвитком складних си- 
стем: зб. наук. праць. Київ, 2010. № 4. C. $19-22$.

9. Тесля Ю. М., Білощицький А. О., Тесля Н. Ю. Інформаційна технологія управління проектами на базі ERPP (enterprise resources planning in project) та APE (administrated projects of the enterprise) систем. Управління розвитком складних систем: зб. наук. праць. Київ, 2010. № 1. С. 16-20.

10. Yehorchenkova N. Yu., Yehorchenkov A. V. Product-resource planning system. IEEE First International Conference on Data Stream Mining \& Processing. Ukraine, Lviv, 2016. P. 29-33.

11. Yehorchenkova N. Yu., Yehorchenkov A. V. Production and project activities modeling module of instrument-making enterprise. 14th International Conference on Advanced Trends in Radioelectronics, Telecommunications and Computer Engineering (TSCET'18). LvivSlavsko, Ukraine, 2018.

12.Егорченкова Н. Ю. Имитационное моделирование в проектной деятельности предприятия. Управління розвитком систем: зб. наук. праць. Київ: КНУБА, 2016. № 26. C. 67-73.

13.Stutko N. Efficiency of information system of project management. URL: http://www.iteam.ru/publications/project/secti on_41/article_2709/

14. Raymond L., Bergeron F. Project management information systems: an empirical study of their impact on project managers and project success. International Journal of Project Management. Amsterdam, Netherlands: Elsevier, 2008. 26 (2). P. 213-220.

15.Project resources management. URL: http://club-energy.ru/e8_3.php

16.Burkov V. N., Novikov D. A. How to manage projects. Moscow: Sinteg, 1997. P. 188.

17. Yehorchenkov A. V., Yehorchenkova N. Yu. Simulation. Information technology and interaction: II international sci.-pract. conf. Ukraine, Kyiv, 2015. P. 130-132.

18.Project portfolio management. URL: https://www.oracle.com/applications/primaver a/products/project-portfoliomanagement/resources.html\#whitepapers

19.Microsoft Project. URL: https://ru.wikipedia.org/wiki/Microsoft_Project

20.ERP. URL: https://ru.wikipedia.org/wiki/ERP

\section{References}

1. Turner, J. Rodney (2007) Guide to projectoriented management. Transl. from Engl. un- der total ed. V. I. Voropaev. Moscow: ID Grebenshchikova, 522 p. [in Russian].

2. Matveev, A. A., Novikov, D. A., Tsvetkov, A. V. (2005) Models and methods of project portfolio management. Moscow: PMSOFT, 206 p. [in Russian].

3. Linenberg, Y, Stadlker, Z, Arbuthnot, S. (2003) Optimizing organizational performance by managing project benefits. PMI Global Congress.

4. Kendall, D. I., Rollins, S. K. (2004) Modern methods: project portfolio management and project management office. St. Petersburg: Peter [in Russian].

5. Teslia, I., Yehorchenkov, O., Khlevna, I., Khlevnyi, A. (2018) Development concept and method of formation of specific project management methodologies. EasternEuropean Journal of Enterprise Technologies, 5/3 (95), pp. 6-16. DOI: https://doi.org/10.15587/17294061.2018.142707

6. Cooper, Robert G., Edgett, Scott J., Kleinschmidt, Elko J. New problems, new solutions: making portfolio management more effective. Research. Technology Management. No. 2. $43 \mathrm{p}$.

7. Yehorchenkova, N. Yu. (2012) Integration of matrix technologies and the method of critical chains in resource management of project portfolios and programs. Upravlinnia rozvytkom skladnykh system: coll. of sci. works. Kyiv, No. 7, pp. 30-35 [in Ukrainian].

8. Teslya, N. Yu. (2010) Creating a portfolio management system for company resources in projects. Upravlinnia rozvytkom skladnykh system: coll. of sci. works. Kyiv, No. 4, pp. 19-22 [in Ukrainian].

9. Teslya, Yu. M., Biloshchitsky, A. O, Teslya, N. I. (2010) Information technology for project management based on ERPP (enterprise resources planning in project) and APE (administrated projects of the enterprise) systems. Upravlinnia rozvytkom skladnykh system: coll. of sci. works. Kyiv, No. 1, pp. 1620 [in Ukrainian].

10. Yehorchenkova, N. Yu., Yehorchenkov, A. V. (2018) Product-resource planning system. IEEE First International Conference on Data Stream Mining \& Processing. Ukraine, Lviv, pp. 29-33.

11.Yehorchenkova, N. Yu., Yehorchenkov, O. V. (2018) Production and project activities modeling module of instrument-making enterprise. 14th International Conference on Advanced 
Trends in Radioelectronics, Telecommunications and Computer Engineering (TSCET'18). Lviv-Slavsko, Ukraine.

12. Yehorchenkova, N. Yu. (2016) Simulation in the project activity of the enterprise. Upravlinnia rozvytkom system: coll. of sci. works. Kyiv: KNUBA. No. 26, pp. 67-73 [in Ukrainian].

13. Stutko, N. Efficiency of information system of project management. URL: http://www.iteam.ru/publications/project/section_41/article_2709/

14.Raymond, L., Bergeron, F. (2008) Project management information systems: an empirical study of their impact on project managers and project success. International Journal of Project Management, Elsevier, 26 (2), pp. 213-220.
15.Project resources management. URL: http://club-energy.ru/e8_3.php

16.Burkov, V. N., Novikov, D. A. (1997) How to manage projects. Moscow, Russia: Sinteg, p. 188.

17. Yehorchenkov, A. V., Yehorchenkova, N. Yu. (2015) Simulation. Information technology and interaction: II international sci.-pract. conf., Kyiv, Ukraine, pp. 130-132.

18.Project portfolio management. URL: https://www.oracle.com/applications/primaver a/products/project-portfoliomanagement/resources.html\#whitepapers

19.Microsoft Project. URL: https://ru.wikipedia.org/wiki/Microsoft_Project

20.ERP. URL: https://ru.wikipedia.org/wiki/ ERPO.

\author{
Ye. V. Yehorchenkov ${ }^{1}, P h D$, associate professor, \\ e-mail: alexee@ukr.net \\ Yu. Kataieva ${ }^{2}, P h D$, associate professor, \\ e-mail:kataevae@ukr.net \\ Yu. L. Khlevna ${ }^{1}, P h D$ \\ e-mail: yuliya.khlevna@gmail.com \\ ${ }^{1}$ Taras Shevchenko National University of Kyiv \\ Volodymirska str., 60/13, Kyiv, 01601, Ukraine \\ ${ }^{2}$ Cherkasy State Technological University \\ Shevchenko blvd, 460, Cherkasy, 18000, Ukraine
}

\title{
CONCEPTUAL APPARATUS OF MANAGEMENT BY PROJECTS AND PROGRAMS PORTFOLIO IN 4P-ENVIRONMENT
}

One of the problems of modern project management is that usually at enterprises for project management various software tools to solve various functional tasks: planning, control, economic and financial evaluation, etc. are used. Traditionally, the tasks of information integration in such systems are considered in the frames of methods of managing information communication in projects. But with the increase of informatization level of project-oriented enterprises, the use of various information systems for solving functional problems is not enough. As a result of the analysis, it was determined that the functionality of modern information technologies for project management does not cover all the functions that are implemented in the process of managing projects, project portfolios and projectoriented sub-programs. Thus, it is necessary to create some technology for managing portfolios, programs, projects and programs that will include uncovered management functions. To implement such a technology, first of all, it is necessary to form a conceptual framework, the basis of which is the conceptual apparatus for managing portfolios of projects and programs in the 4P-environment. Therefore, in the article it is proposed to create a conceptual apparatus for portfolio management of projects and programs of project-oriented enterprises, which unites the areas of project and organization management into a single functional environment - 4P-environment. Scientific and methodological basis for the construction of $4 P$-environment is necessary to create structures, algorithms, tools and processes of functional add-ons over project management tools at project-oriented enterprises on the basis of developed models and methods. Per se, such basis will enable to create a set of functional operators which will satisfy the need of project management in modern information management technology.

Keywords: 4P-environment, projects and programs portfolio, project management, information technologies. 